\title{
Metastasis of Retinoblastoma to the Parotid Gland: A Case Report
}

\author{
Said Anajar*, Tatari Moutaa Mohammed, Redallah Abada , Mohammed Roubal and Mohammed Mahtar \\ Service ORL et chirurgie cervico-faciale - Hôpital 20 Août, Maroc
}

Submission: April 17, 2017; Published: April 24, 2017

*Corresponding author: Said Anajar, Service ORL et chirurgie cervico-faciale - Hôpital 20 Août, BD bordeaux rue ait baha N 5 Casablanca Maroc, Tel: 212660782808; Email: Anajar.said.med@gmail.com

\begin{abstract}
Introduction: Retinoblastoma is the most common intraocular tumor of the child. Metastasis to the parotid gland is very rare. There are only 5 cases previously reported in the literature and because of their rarities and the relative lack of data on their management, there is no clearly defined treatment algorithm.

Case Report: We report a case of a 4 years-old child operated for retinoblastoma who received adjuvant chemotherapy, and presented 9 months after her surgery, parotid metastasis of retinoblastoma for which she underwent a total parotidectomy with preservation of facial nerve, and lymph node dissection.

Discussion and Conclusion: The aim of this case is to discuss the clinical, para-clinical and pathological characteristics, confirming the poor prognosis of secondary tumors of the parotid, especially with metastatic lymph node.

Keywords: Retinoblastoma; Metastasis; Parotid gland; Case report
\end{abstract}

\section{Introduction}

Retinoblastoma is the most common intraocular tumor of the child. It can be unilateral or bilateral. Classically it is presented by a leukokoria, but several signs can be found. The most common metastasis sites are bone, spinal cord and meninges. However, metastasis to the salivary glands remains rare. To our knowledge there are 5 cases previously reported in the literature [1]. The aim of this work is to report the clinical, para-clinical and pathological features of this exceptional metastasis.

\section{Case Report}

It is about a 4 years old child, operated one year ago for retinoblastoma of the right eye by enucleation followed by sessions of chemotherapy. He presented 3 months before admission in our department a right parotid mass progressively increasing in volume. This mass was hard and fixed, measuring $5 \mathrm{~cm}$ of major axis, without palpable lymph nodes. A cervical CT scan showed an enlarged right parotid gland, with several nodules suspected of malignancy, and infra-centimetric lymph nodes on the right side of the neck (Figure 1). A total parotidectomy with preservation of the facial nerve with homolateral cervical lymph node dissection was performed. The histology found an undifferentiated nodule in the parotid gland with metastatic lymph nodes.

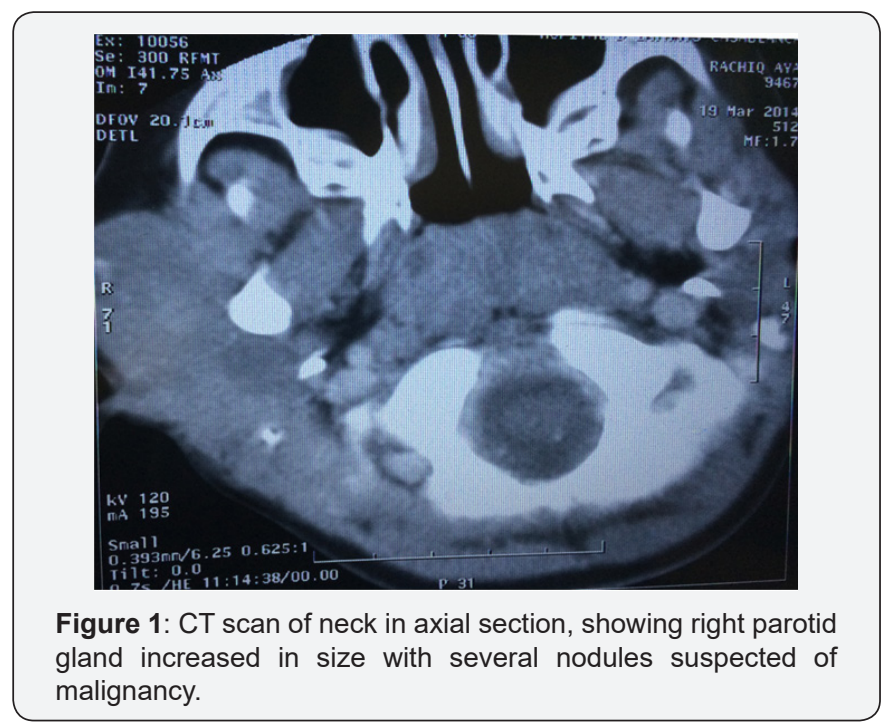

The architecture of the nodule (Figure 2) consisted of small to medium sized cells with indistinct cytoplasm and 


\section{Global Journal of Otolaryngology}

irregular hyperchromic cores, with foci of necrosis and FlexnerWintersteiner rosettes images. The immunohistochemical study showed negativity to antileukocyte, antidesmine, antimyogenin and anti-PS 100 antibodies, and focal positivity to synaptophysin. Molecular biology could not be achieved due to a lack of resources. So, metastasis of a retinoblastoma was retained. The patient was subsequently referred to pediatric oncology for chemotherapy.

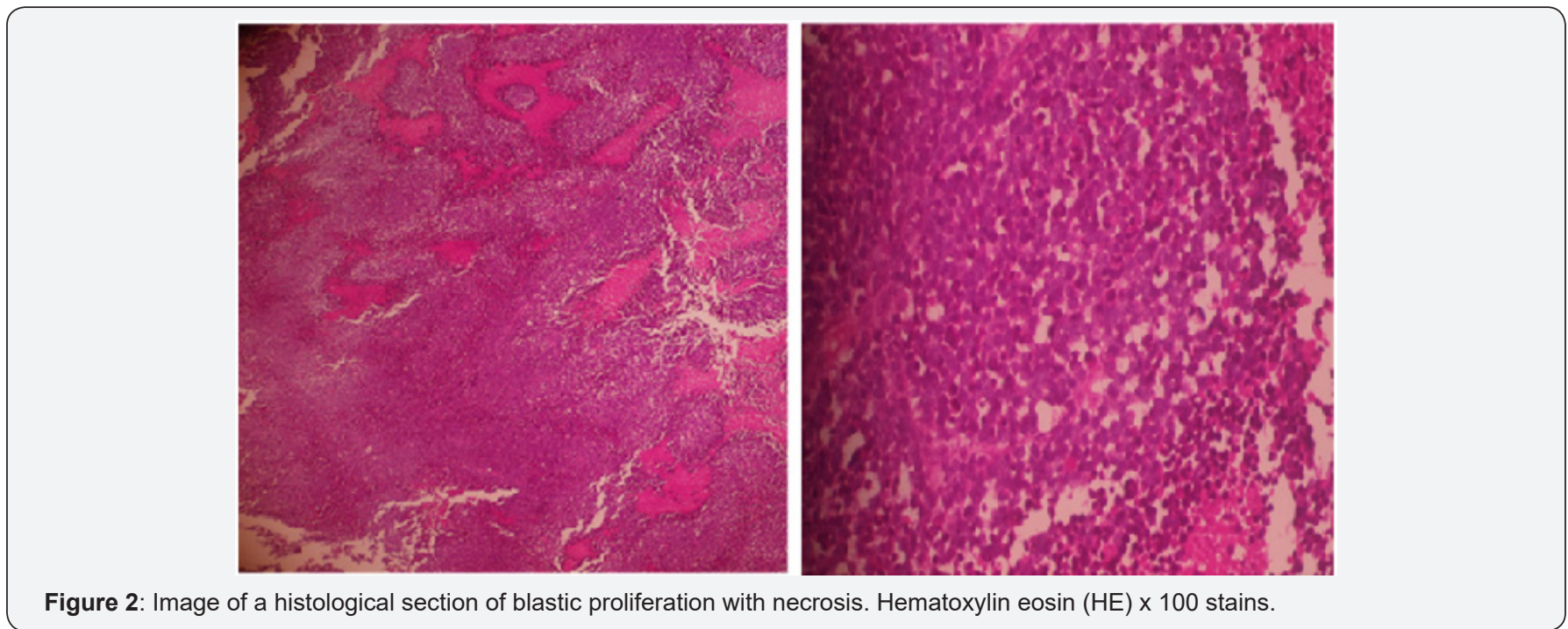

\section{Discussion}

Although intra-parotidial metastases of epithelial tumors are commonly encountered in the head and neck region, it is rare to find metastases of orbital tumors in this region. Ocular structures should be included in the examination of intra-parotid metastases when there is no apparent origin of a primary tumor [2]. In order of decreasing frequency, primitive cervical-facial lesions giving parotid metastases are represented by melanomas (40\%), epidermoid epitheliomas (33\%) and cutaneous epitheliomas [3]. Cancers of the thyroid, hypo-pharynx, ethmoid and lacrimal glands give less frequent secondary malignant lesions of the parotid. In addition, the parotid gland should be examined in front of any diagnosed malignant primary orbital tumor [2,3]. Retinoblastoma has an incidence of $0.006 \%$ [1]. It can be classified into two types; Unilateral and bilateral.

Kitchin, reported that 38 cases of secondary malignancies were found in 800 cases of bilateral retinoblastoma, an incidence of $4.8 \%$ [4]. The most common site of retinoblastoma metastasis is the intracranial region, accounting for about $50 \%$ of the cases. These tumors metastasize by pre-auricular lymph nodes and cervical lymph nodes only when tumor growth is extended to the orbit and the face [5]. Fine needle cytology has proved its value in the evaluation of head and neck lesions and is an aid in precise preoperative diagnosis [1]. Also, the cytological diagnosis guides the histological diagnosis. Radiological examinations, CT and MRI are used to determine the type of parotidectomy to be performed [6]. In fact, some studies demonstrate the value of high-resolution magnetic resonance imaging (MRI) in the diagnosis, staging, and follow-up of retinoblastoma for conservative treatment.
It has the potential to detect small intraocular seeds, hemorrhage and metastatic risk factors not visible to the fundus of eye, as well as response to treatment. Unfortunately, the diagnostic accuracy of MRI is not perfect, especially for subtle intraocular seeds or minimal invasions of the optic nerve. The most important application of MRI is the detection of metastatic risk factors, which cannot be detected by ophthalmoscopy or ultrasound [6]. Optimal treatment of parotid metastases is not defined. Like most authors, Malata et al. [7] proposes a superficial parotidectomy with preservation of the facial nerve when the metastatic disease is limited to the superficial lobe. A total parotidectomy with sacrifice of the facial nerve should be considered when there is an involvement of the deep lobe and / or the facial nerve. This therapeutic approach is also supported by McKean et al. $[7,8]$. In the past, the survival of a patient with a diagnosis of metastatic retinoblastoma was rare. There are some encouraging reports that intensive chemotherapy combined with total body irradiation and intrathecal chemotherapy has been associated with long-term survival [9].

\section{Conclusion}

Among the major salivary glands, the parotid is the most common site for tumor metastasis. This is due to the presence of intraparotid lymph nodes and the potential for contiguous propagation from neoplasms of the neck and head. The secondary localization of a retinoblastoma is rare, and its prognosis remains sombre.

\section{References}

1. Khademi B, Derakhshandeh V, Vasei M, Torabi S (2003) Metastasis of retinoblastoma to the parotid gland: diagnosis by fine needle aspiration cytology. Otolaryngol Head Neck Surg 128(2): 296-297. 
2. Buenechea R, Garatea J, Castro-Forns M, Bassas C (1993) Parotid Gland Metastases From Orbital Tumors: Report Of Two Cases. J Oral Maxillofac Surg 51(5): 570-574.

3. Marvel JB, Schwartz MR, Donovan DT (1990) Metastatic Squamous Cell Carcinoma of the Parotid: A Case of an Occult Primary. Head Neck 12: 174-177.

4. Kitchin FD, Ellsworth RM (1974) Pleiotropic Effect of the Gene for Retinoblastoma. J Med Genet 11-244.

5. Koji Ebata, Hideki Mizutani, Toshio Kaneda (1991) Metastatic Retinoblastoma To The Orofacial Region. J Oral Maxillofac Surg 49(10): 1120-1123.

This work is licensed under Creative Commons Attribution 4.0 License

DOI: $10.19080 /$ GJ0.2017.07.555702
6. De Jong MC, De Graaf P, Brisse HJ, Galluzzi P, Göricke SL, et al. (2015) The Potential of 3T High-Resolution Magnetic Resonance Imaging For Diagnosis, Staging, And Follow-Up Of Retinoblastoma. Surv Ophthalmol 60(4): 346-55.

7. Malata CM, Camilleri IG, Mclean NR, Piggott TA, Soames JV (1998) Metastatic Tumors Of The Parotid Gland. J Oral And Maxillofa Cail Surg 36(3): 190-195.

8. Mckean ME, Lee K, McGregor IA (1985) The Distribution of Lymph Nodes in and Around the Parotid Gland: An Anatomical Study. J Plast Surg 38: 1-5.

9. Dequanter D, Lothaire Ph, Andry G (2005) Les Tumeurs Malignes Secondaires De La Parotide. Otolaryngol Chir Cervicofac 122: 18-20.

Your next submission with Juniper Publishers will reach you the below assets

- Quality Editorial service

- Swift Peer Review

- Reprints availability

- E-prints Service

- Manuscript Podcast for convenient understanding

- Global attainment for your research

- Manuscript accessibility in different formats ( Pdf, E-pub, Full Text, Audio)

- Unceasing customer service

Track the below URL for one-step submission https://juniperpublishers.com/online-submission.php 